\title{
Systemically Induced Resistance and Microbial Competitive Exclusion: Implications on Biological Control
}

\author{
A. Martinuz, A. Schouten, and R. A. Sikora
}

Institute for Crop Science and Resource Conservation (INRES), Department of Plant Health, Soil Ecosystem Phytopathology and Nematology Laboratory, University of Bonn, Nussallee 9, 53115 Bonn, Germany. Accepted for publication 25 August 2011.

\section{ABSTRACT}

Martinuz, A., Schouten, A., and Sikora, R. A. 2012. Systemically induced resistance and microbial competitive exclusion: Implications on biological control. Phytopathology 102:260-266.

The root-knot nematode, Meloidogyne incognita, is among the most damaging agricultural pests, particularly to tomato. The mutualistic endophytes Fusarium oxysporum strain Fo162 (Fo162) and Rhizobium etli strain G12 (G12) have been shown to systemically induce resistance toward $M$. incognita. By using triple-split-root tomato plants, spatially separated but simultaneous inoculation of both endophytes did not lead to additive reductions in $M$. incognita infection. More importantly, spatially separated inoculation of Fo162 and G12 led to a reduction in Fo162 root colonization of 35 and 39\% when G12 was inoculated on a separate root section of the same plant in two independent experiments. In an additional split-root experiment, spatial separation of Fo162 and G12 resulted in a reduction of Fo162 root colonization of approximately 50\% over the water controls in two independent experiments. The results suggested that the suppressive activity of G12 on Fo162 and M. incognita is possibly related to the induction of specific plant defense mechanisms. Thus, although Fo162 and G12 have the ability to systemically repress $M$. incognita infection in tomato, they can be considered incompatible biocontrol agents when both organisms are present simultaneously on the same root system.
In nature, competitive exclusion is a common phenomenon that regulates the populations of a wide range of organisms in the rhizosphere and in the phyllosphere of plants $(36,37)$. Competition for space and nutrients, in some cases, is also a mechanism responsible for biological control of root pathogens and nematodes (1). Therefore, the "first-come first-served" nature of colonization and the principles of survival of the fittest are factors that could impact the effectiveness of biological control when multiple inoculants are needed for effective pest management. Studies on the competition between biological control agents in the rhizosphere and/or endorhiza as it influences biological control efficacy is for the most part unknown. In the few instances where cocktails of microbes have been applied to seed or planting material, often no significant synergistic or additive increases in control were observed (37).

A wide range of beneficial rhizosphere and endophytic fungi and bacteria have been reported to have biological control activity toward nematodes $(2,17,33,35)$. The fungus Fusarium oxysporum strain Fo162 and the endophytic bacterium Rhizobium etli strain G12 have been shown to systemically induce resistance toward the root-knot nematode, Meloidogyne incognita (36). The microbial basis for the reduction in nematode damage is regulated by the type and intensity of the mechanism of suppression (36). Suppression has been shown to be due to: the production of toxic secondary metabolites, competitive exclusion, competition for nutrients, repellent components of root exudates, induced resistance, or a combination of these elements $(2,17,18,20,33,39,40)$.

Induced resistance can be local or systemic; in the latter case the entire plant becomes resistant toward a pathogen (9). The presence of systemically induced defense responses as a mode-ofaction involved in suppression of plant-parasitic nematodes is

Corresponding author: A. Martinuz; E-mail address: martinuz@ catie.ac.cr

http://dx.doi.org/10.1094/PHYTO-04-11-0120

(c) 2012 The American Phytopathological Society usually determined in split-root systems (34). In these experiments, the presence of induced resistance is measured by first inoculating a biocontrol agent at the inducer side of the root system and subsequently introducing the nematode at the responder side of the root system. Afterward, the nematode penetration and/or development are quantified $(34,35,36)$. For instance, $\mathrm{Vu}$ et al. (42) and Dababat and Sikora (4) demonstrated the existence of systemic resistance, caused by the presence of the endophytic $F$. oxysporum Fo162, toward the burrowing nematode, Radopholus similis, in banana and $M$. incognita in tomato. Similarly, HaskyGünther and Sikora (13) and Schäfer et al. (31) reported the involvement of systemic resistance in interaction studies with the endophytic bacteria Bacillus sphaericus B43 and R. etli G12 for control of the cyst nematode, Globodera pallida, on potato and $M$. incognita on tomato. In all cases, the presence of the endophytes at the inducer side of a split-root plant resulted in lower juvenile penetration at the responder side (35).

The level of nematode control is often considered to be caused by variation in the intensity of endophyte root colonization or activity of the endophyte within the plant at critical points in the nematode infection process. In order to overcome this limitation, the combining of biocontrol agents has been considered, in which different microorganisms that evoke different defense responses in the plant to enhance biocontrol activity $(7,23,29,37)$. Such an approach has resulted in an increased protection level against $R$. similis in banana when $B$. firmus and $F$. oxysporum Fo162 or Paecilomyces lilacinus and $F$. oxysporum Fo162 were combined (23). Conversely, the use of combined inoculation of $F$. oxysporum Fo162 and Glomus coronatum did not lead to additive or synergic levels of $M$. incognita control in tomato (6). This variation in success may indicate that the biocontrol agents in the combined application affect each other, thus influencing the outcome of the pathogen control level. The objectives of the present investigations were to study the systemic interrelationships between the endophytic fungus $F$. oxysporum Fo162, the endophytic bacterium $R$. etli $\mathrm{G} 12$, and the root-knot nematode $M$. incognita 
on tomato using plants with two- and threefold split-root systems to ensure spatial separation of the biocontrol agents.

\section{MATERIALS AND METHODS}

Plants. Tomato cultivar Moneymaker (Solanum lycopersicum), which is susceptible to $M$. incognita, was used in all experiments. Seeds were surface-sterilized by first submersing them in a $75 \%$ ethanol solution for $1 \mathrm{~min}$ followed by a $3 \mathrm{~min}$ soak in a $1.5 \%$ sodium hypochloride $(\mathrm{NaOCl})$ solution. Then the seeds were rinsed with autoclaved water. Sterile seeds were sown in 35-well multi-pot trays containing sand autoclaved at $121^{\circ} \mathrm{C}$ for $1 \mathrm{~h}$ and aerated for 2 days before use. The planting trays were maintained in a growth chamber at $25 \pm 3^{\circ} \mathrm{C}$ with $16 \mathrm{~h} \mathrm{day}^{-1}$ diurnal light, 60 to $70 \%$ humidity, and fertilized weekly with $5 \mathrm{ml}$ of a commercial fertilizer (14-10-14, $2 \mathrm{~g} \mathrm{liter}^{-1}$ ) (AGLUKON, Düsseldof, Germany). After 4 weeks, the tomato plantlets were transplanted into $11 \mathrm{~cm}$ plastic pots containing $300 \mathrm{~g}$ of autoclaved sand-soil, mixed 2:1 (vol:vol), and transferred to a greenhouse set at $27 \pm$ $3^{\circ} \mathrm{C}$ and $16 \mathrm{~h} \mathrm{day}^{-1}$ diurnal light.

Nematodes. The root-knot nematode $M$. incognita was used in all experiments and was supplied by Dr. D. Dickson (University of Florida, Gainesville). Nematodes were maintained on a susceptible tomato, cultivar Furore, and continuously propagated in a greenhouse $\left(27 \pm 5^{\circ} \mathrm{C}\right)$ production system in a large container containing sandy loam soil; the temperature in soil was $24 \pm 1^{\circ} \mathrm{C}$. Nematode eggs were extracted from 2-month-old heavily galled tomato roots using a modified extraction technique described by Hussey and Barker (16). Roots were washed of soil with water, cut into $1-\mathrm{cm}$ pieces, macerated for $20 \mathrm{~s}$ at high speed $(11,000$ rpm) in a blender (Ultra Turrax T25, Whatman GmbH, Dassel, Germany), and collected in a glass bottle. $\mathrm{NaOCl}$ was added to a final concentration of $1.5 \%$ and the bottle was shaken vigorously for $3 \mathrm{~min}$. To remove the $\mathrm{NaOCl}$, this suspension was then thoroughly rinsed with tap water through a set of sieves with mesh sizes of $250,100,45$, and $25 \mu \mathrm{m}$. The eggs retained on the $25 \mu \mathrm{m}$ mesh sieve were collected in tap water. The egg suspension was continuously oxygenated for 10 days using an aquarium pump to induce second-stage juvenile (J2) hatching. To separate the active juveniles from unhatched eggs and dead juveniles, the suspension was placed on a Baermann funnel for $24 \mathrm{~h}$ (15). The active $\mathrm{J} 2$ were adjusted to 1,000 juveniles per $5 \mathrm{ml}$ and immediately used for inoculation purposes.

F. oxysporum strain Fo162. The mutualistic endophyte $F$. oxysporum strain Fo162, subsequently referred to as Fo162, was originally isolated from the cortical tissue of surface-sterilized tomato roots of cultivar Moneymaker in Kenya (10) and stored at $-80^{\circ} \mathrm{C}$ using the microbank preservation system (Cryobank, Mast Group Ltd., Merseyside, UK). Fungal inoculum was produced by transferring Fo162 colonized beads onto potato dextrose agar (PDA; Difco, Sparks, MD) plates (90 mm diameter), supplemented with $150 \mathrm{mg}$ liter $^{-1}$ of each streptomycin sulfate and chloramphenicol to avoid bacterial contamination. To produce inoculums, Fo162 cultures were incubated for 3 weeks at $25^{\circ} \mathrm{C}$ in the dark. The mycelium and conidia formed were then scraped from the media surface with a spatula and suspended in autoclaved distilled water at $121^{\circ} \mathrm{C}$ for $20 \mathrm{~min}$. Spores were separated from the mycelium by sieving the content through four layers of fine sterile cheesecloth. Spore density was determined with a hemacytometer (Thomas Scientific, Philadelphia, PA) and spore density was adjusted with sterilized water to $1 \times 10^{6} \mathrm{CFU} \mathrm{g}^{-1}$ of soil.

$\boldsymbol{R}$. etli strain G12. The endophytic bacterium $R$. etli strain G12, subsequently referred to as G12, was originally isolated from the rhizosphere of potatoes (28) and initially identified as Agrobacterium radiobacter, but renamed $R$. etli G12 (12). The bacterium was stored at $-80^{\circ} \mathrm{C}$ using the microbank preservation system. For production of inoculum, G12 was grown on solid King's
B agar medium (90 mm petri plates) for $36 \mathrm{~h}$ at $28^{\circ} \mathrm{C}$ in the dark (19). This preculture was then used to inoculate $100 \mathrm{ml}$ of liquid King's B medium in an Erlenmeyer flask. G12 was cultured for $36 \mathrm{~h}$ at $28^{\circ} \mathrm{C}$ on a rotary shaker at $100 \mathrm{rpm}$ in the dark. The bacterial suspension was centrifuge at $5,000 \times g$ for $20 \mathrm{~min}$ at $10^{\circ} \mathrm{C}$. The resulting pellet was resuspended in sterile 0.25 strength Ringer-solution (Merck, Darmstadt, Germany) and the bacterial density adjusted to 2 at $560 \mathrm{~nm}$, representing approximately $1.2 \times$ $10^{10} \mathrm{CFU} \mathrm{ml}^{-1}(12,29,30)$.

Experimental designs. Triple-split-root system. The shoots of 6-week-old tomato plants (height $36 \mathrm{~cm}$ ) were completely detached from their respective root system and the basal part of the shoot (diameter $0.5 \mathrm{~cm}$ ) split longitudinally into three sections, over $7 \mathrm{~cm}$ in length. Each section $(6 \mathrm{~cm})$ was replanted in a separate $11-\mathrm{cm}$ pot filled with $300 \mathrm{~g}$ of autoclaved soil and each pot was separated approximately $1 \mathrm{~cm}$ to guarantee complete physical separation (Fig. 1). The lower leaves were pruned to reduce transpiration during the growth of adventitious roots. The triple-split-rooted plants were maintained in a greenhouse for 2 weeks at $27 \pm 3^{\circ} \mathrm{C}$ with $16 \mathrm{~h} \mathrm{day}^{-1}$ diurnal light and temperature in pots was $25 \pm 2{ }^{\circ} \mathrm{C}$.

Two sections of the triple-split-root plants were then labeled 'inducer' and the third section was labeled 'responder' (Fig. 1). One inducer root section was inoculated with Fo162, and the other inducer section was inoculated with G12. Three controls were included in the experiment in which both of the inducer sections were inoculated with Fo162, G12, or water (Fig. 1). Fo162 was applied as a spore suspension in $5 \mathrm{ml} \mathrm{pot}^{-1}$ at a concentration of $1 \times 10^{6} \mathrm{CFU} \mathrm{^{-1 }}$ of soil. The inoculum was dispensed into three holes around the selected inducer section and inoculation was repeated 2 weeks later as previously described by Dababat and Sikora (5) and Mendoza and Sikora (23). G12 was applied with $5 \mathrm{ml} \mathrm{pot}^{-1}$ of a bacterial suspension $\left(\mathrm{OD}_{560}=2\right)$ as a drench around the inducer section of the plant and inoculation was repeated 2 weeks later as described by Reimann et al. (29). For the water control, $5 \mathrm{ml}$ of sterilized water was used. Four weeks after the first inoculation, the responder section of each plant was inoculated with a $5 \mathrm{ml}$ suspension containing 1,000 $\mathrm{M}$. incognita $\mathrm{J} 2$. The nematode suspension was dispensed into three 2-cm-deep holes around the responder root section.

Treatments were replicated six times and the experiment was conducted twice. The plants were arranged in a completely randomized design in the same greenhouse at $27 \pm 3^{\circ} \mathrm{C}$ with $16 \mathrm{~h}$ day $^{-1}$ diurnal light. Two weeks after nematode inoculation, inducer roots, responder roots, and shoots were collected separately and their weight determined. Nematode penetration was determined by staining the responder roots with $0.1 \%$ acid fuchsin solution, followed by heating to boiling using a microwave for 1.5 to $2 \mathrm{~min}(5,8)$. After cooling for $60 \mathrm{~min}$, excess acid fuchsin was removed by rinsing the roots with tap water. The roots were then macerated twice for $10 \mathrm{~s}$ in $25 \mathrm{ml}$ of water at high speed $(11,000$ rpm) using an Ultra Turrax T25 (Whatman GmbH, Dassel, Germany). The macerated root suspension was adjusted to $100 \mathrm{ml}$ with tap water and thoroughly mixed by shaking. From this, two winding-track counting trays (15) were immediately filled with $10-\mathrm{ml}$ aliquots each. The number of penetrated J2 was then counted under a stereomicroscope (100× magnification) and the total number of $\mathrm{J} 2$ per root system calculated.

To determine Fo162 colonization in the inducer root sections, the roots were surface-terilized by submersion in a $1.5 \% \mathrm{NaOCl}$ solution for $3 \mathrm{~min}$, followed by three rinses in sterile distilled water. The roots were then imprinted on PDA to verify surface sterilization (38). The surface-sterilized inducer roots were then cut into $0.5 \mathrm{~cm}$ sections and 18 root segments per treatment were randomly selected and placed on two petri plates $(150 \mathrm{~mm}$ diameter) containing PDA medium, supplemented with $150 \mathrm{mg} \mathrm{liter}^{-1}$ of each streptomycin sulphate and chloramphenicol. After 4 to 7 days of growth at $25^{\circ} \mathrm{C}$ in the dark, fungi emerging from each 
root segment were phenotypically verified as being Fo162. These data were used for calculating the percentage of root colonization per inducer root section, i.e., (the number of root segments colonized by Fo162/total number of root segments) $\times 100(23)$. The density of G12 was not determined due to the similarity of the colonies with other root inhabiting microorganisms.

Split-root system. The shoots of 6-week-old tomato plants (height $36 \mathrm{~cm}$ ) were detached from the root system and the basal part of the shoot (diameter $0.5 \mathrm{~cm}$ ) was longitudinally split into two sections over $7 \mathrm{~cm}$ in length. Each section was placed in a separate $11 \mathrm{~cm}$ pot and filled with $300 \mathrm{~g}$ of autoclaved soil (Fig. 2 ). The lower leaves were pruned to reduce transpiration during the growth of the adventitious roots. The split plants were kept in a greenhouse for 2 weeks under the same condition as previously indicated for growth of adventitious roots.

The inducer side of the two roots was inoculated with either Fo162 or G12. The roots at the responder side remained untreated. Plants treated with tap water at the inducer side served as controls. Fo162, G12, and water control were applied as described above. One week after inoculation, the roots at the responder side were treated with a spore suspension of Fo162 as described above. Each treatment was replicated six times and the experiment conducted twice. The plants were arranged in a completely randomized design in a greenhouse under the conditions previously indicated. Four weeks after inoculating the inducer root sections, the roots from both the inducer and responder side were separated from soil substrate with tap water and root and shoot fresh weights were recorded. Root colonization by Fo162 at the responder side was determined by the surface sterilization and imprint method, followed by plating on PDA as described in the previous section.

Data analysis. Penetrated nematodes and Fo162 percentage of root colonization were tested for homoscedasticity after pooling data from repeated experiments by an $F$ test of equality of variances at $P \leq 0.05$. When the $F$ test of equality of variances was significant, data from the two experiments were further analyzed separately. The $F$ test of equality of variances was significant for penetrated nematodes $(P=0.049)$ and Fo162 percentage of root colonization in the triple-split-root experiment $(P=0.063)$ and in the split-root experiment $(P=0.0093)$. Data from each repeated experiment were then tested for normality and homoscedasticity prior to statistical analysis. For the triple-split-root experiment, penetrated nematodes were square-root transformed before statistical analysis and back transformed after analysis, while for Fo162 percentage of root colonization in both triple-split-root and split-root experiments, statistical analysis was performed on untransformed data. One-way analysis of variance (ANOVA) was used to demonstrate differences in penetrated nematodes and Fo162 percentage of root colonization between individual treatments. When the ANOVA test was significant, the mean values per treatment were compared using the least significant difference test (LSD) at $P \leq 0.05$. Data obtained on Fo162 percentage of root colonization from the triple-split-root experiment were analyzed according to a $t$ test for comparing two independent samples at

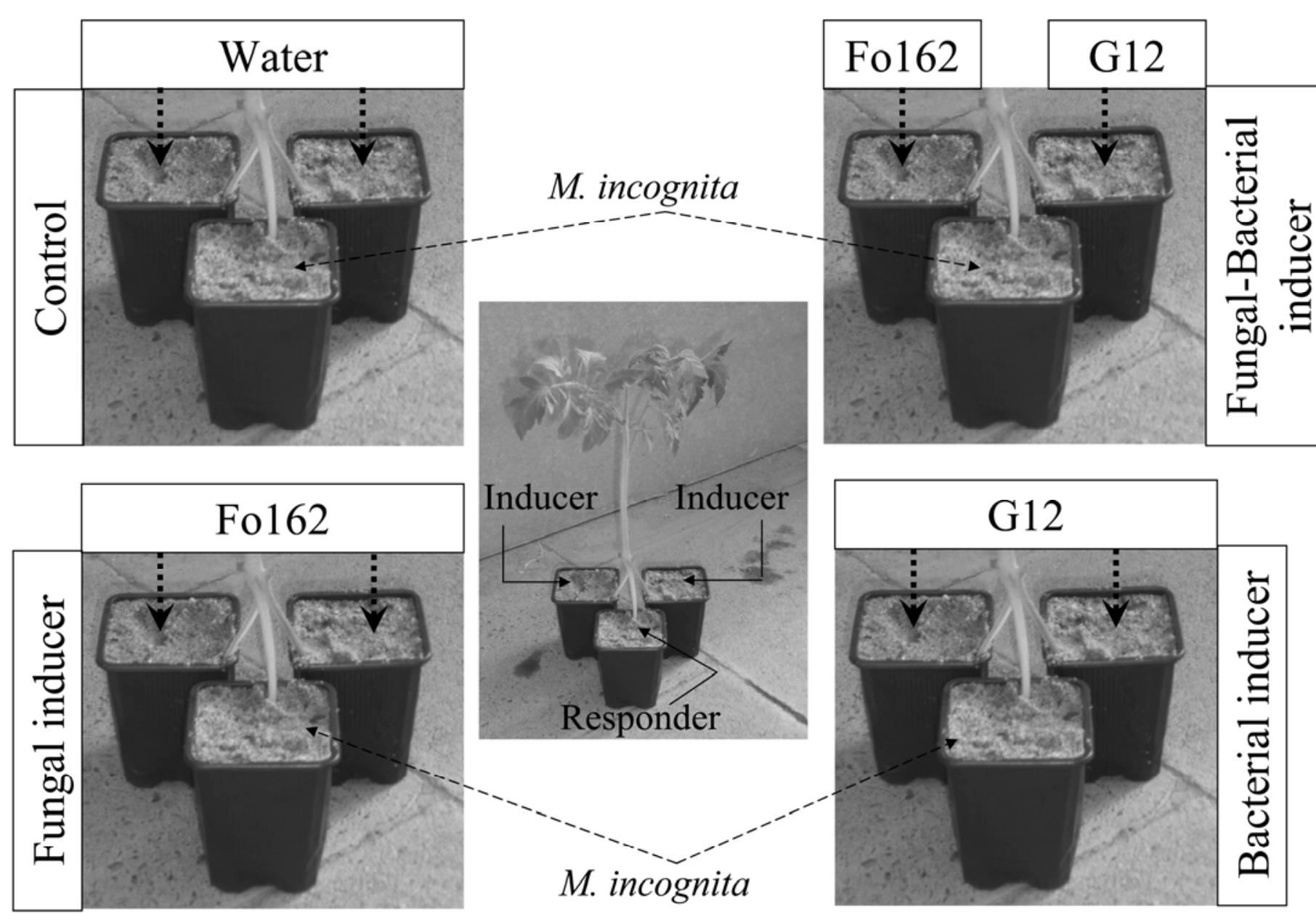

Fig. 1. Triple-split-root system used to study systemically induced resistance in spatially separated co-inoculated Fusarium oxysporum strain Fo162 (Fo162) and Rhizobium etli strain G12 (G12) toward Meloidogyne incognita on tomato. Six-week-old tomato plants detached from their root system were split longitudinally in three sections and each section was placed in a separated pot. Two weeks after, one inducer root section was treated with Fo162 and the other inducer root section was treated with G12. Three controls were included, in which both inducer root sections were inoculated with Fo162, G12, or water. Four weeks after, the responder root section of each plant was inoculated with $M$. incognita. 
$P \leq 0.05$. All statistical analyses were performed using the statistical software InfoStat/Professional version 2009 (InfoStat Group, FCA, AR).

\section{RESULTS}

Influence of spatial separated inoculation of Fo162 and G12 on $M$. incognita penetration and endophyte colonization. A triple split-root experiment was used to monitor the ability of Fo162, G12, or a combination of the two endophytes to reduce systemically $M$. incognita penetration when all organisms were separately inoculated (Fig. 1). Two weeks after nematode inoculation, M. incognita penetration in the responder section of the triple-split-root system was reduced significantly following fungal inducer, bacterial inducer, and both fungal and bacterial inducer in experiment $1(P=0.0006, \mathrm{LSD}=24.61)$ and experiment $2(P=$ 0.0052 , LSD $=108.86)$ when compared with the nematode penetration of control plants treated with water (Fig. 3). However, the number of penetrated nematodes detected on those roots treated with Fo162 at one side and G12 at the other (Fig. 3; fungalbacterial inducer) was nonsignificantly different when compared with those that were treated with either G12 or Fo162 at both inducer sides in either of the two experiments (Fig. 3).

In both experiments, reisolation of Fo162 from the Fo162 inoculated section of the root system revealed a reduction in root colonization of 35\% $(P=0.0164)$ and $39 \%(P=0.0306)$ when G12 was inoculated on a separate inducer root section in experiments 1 and 2, respectively (Fig. 4). Fo162 was neither detected in the water inoculated (control) root sections nor in the root sections inoculated with G12. No differences in root and shoot weight were observed among the various treatments when compared with the control (data not shown).

Influence of G12 on the colonization of Fo162 after spatial separated inoculation of both endophytes. A standard split-root experiment was used to evaluate the ability of G12 to systemically repress Fo162 root colonization when both endophytes were separately inoculated (Fig. 2). Four weeks after Fo162 inoculation on the responder side of the split-root system, systemic inhibition of Fo162 root colonization was observed. In the presence of G12 at the inducer side, the percent colonization by Fo162 on the responder side was repressed approximately $50 \%$ when compared with the water controls in the two experiments (experiment $1, P=$ $0.0147, \mathrm{LSD}=5.76$; experiment $2, P=0.0432, \mathrm{LSD}=12.01$ ) (Fig. 5). Inoculation of the inducer section of the root system with water or with Fo162 had no significant effect on Fo162 colonization on the responder side. In this case, the level of Fo162 colonization on the responder side was 17.8 and $22.2 \%$ in experiments 1 and 2, respectively, which was similar to the levels of colonization obtained with water as the inducer, being 15.6 and $25.0 \%$ in both experiments, respectively (Fig. 5). No differences in root or shoot weight were observed among the treatments when compared with the control (data not shown).

\section{DISCUSSION}

The results from the current study confirmed the ability of both Fo162 and G12 to systemically repress $M$. incognita colonization in tomato $(4,12,31,42)$. The simultaneous and spatially separated application of both biocontrol agents to the individual inducer sides of the triple-split-root system resulted in a significant reduction of $M$. incognita penetration at the responder side of the triplesplit-root system. However, as already reported in a nonseparated approach $(6,22,23)$, this reduction was not greater than the levels of control obtained in treatments with the individual biocontrol agents. Thus, even when applied in a spatial way, the two biocontrol agents cannot improve $M$. incognita biological control in tomato.

Remarkably, the presence of G12 on one inducer root section significantly reduced Fo162 colonization in the roots of the other spatial separated inducer root section. This systemically induced antagonistic activity of the bacterial endophyte G12 toward the fungal endophyte Fo162 was confirmed in an additional split-root experiment. These results demonstrated that G12 not only negatively influenced $M$. incognita infection processes, but also the colonization of Fo162. By using a split-root system to study the induction of systemic resistance produced by two plant growthpromoting rhizobacteria, Pseudomonas putida and Serratia marcescens, Liu et al. (21) demonstrated that both rhizobacteria delayed Fusarium wilt disease symptoms caused by $F$. oxysporum f. sp. cucumerinum. Mwangi et al. (24) also showed that $B$. sphaericus B43 was able to induce systemic resistance to another Fusarium wilt pathogen, F. oxysporum f. sp. lycopersici. Moreover, van Peer and Schippers (41) identified associated lipopolysaccharides, short-chain sugar molecules in the outer cell wall membrane of a species of rhizobacterium Pseudomonas, which induced resistance against Fusarium wilt caused by $F$. oxysporum f. sp. dianthi in carnation. Apparently, some bacteria are able to induce resistance in plants toward a number of $F$. oxysporum species, regardless of their pathogenic or nonpathogenic colonization behavior. These findings demonstrate that some biocontrol agents may be incompatible when used on the same host $(6,7,25)$. In such cases, they may even directly or indirectly negatively affect biocontrol efficacy.

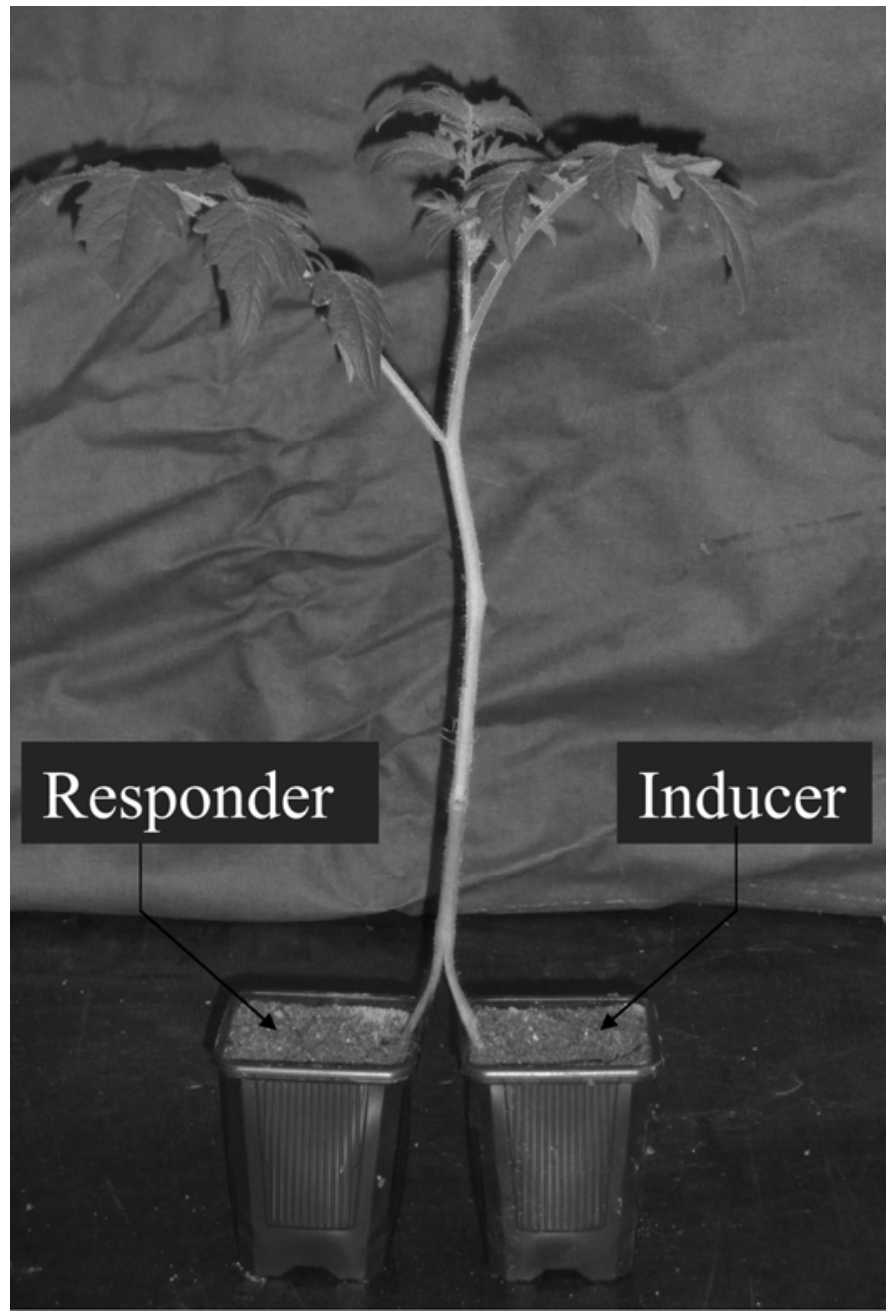

Fig. 2. Split-root system used to study systemically induced resistance of Rhizobium etli strain G12 (G12) toward Fusarium oxysporum strain Fo162 (Fo162) on tomato. Six-week-old tomato plants detached from their root system were split longitudinally in two sections and each section was placed in a separated pot. Two weeks after, the inducer section of the two roots was treated with Fo162, G12, or water. One week after, the responder section of the two roots was treated with Fo162. 
In split-root experiments, Selim (32) demonstrated systemically induced resistance toward $M$. incognita in tomato after treatment of the inducer half with salicylic acid (SA), methyl jasmonate or Fo162. It was concluded that both jasmonic acid (JA)- and SAdependent signaling pathways were involved in induced resistance against $M$. incognita in tomato, suggesting that both sys- temic acquired resistance (SAR) and induced systemic resistance (ISR) are the pathways that are involved in antagonism toward the nematode. In contrast, Siddiqui and Shaukat (34) encountered evidence for a SAR-independent pathway that was responsible for the systemic resistance toward nematodes induced by $P$. aeruginosa $7 \mathrm{NSK} 2$ and $P$. fluorescens CHA0. They suggested that ISR
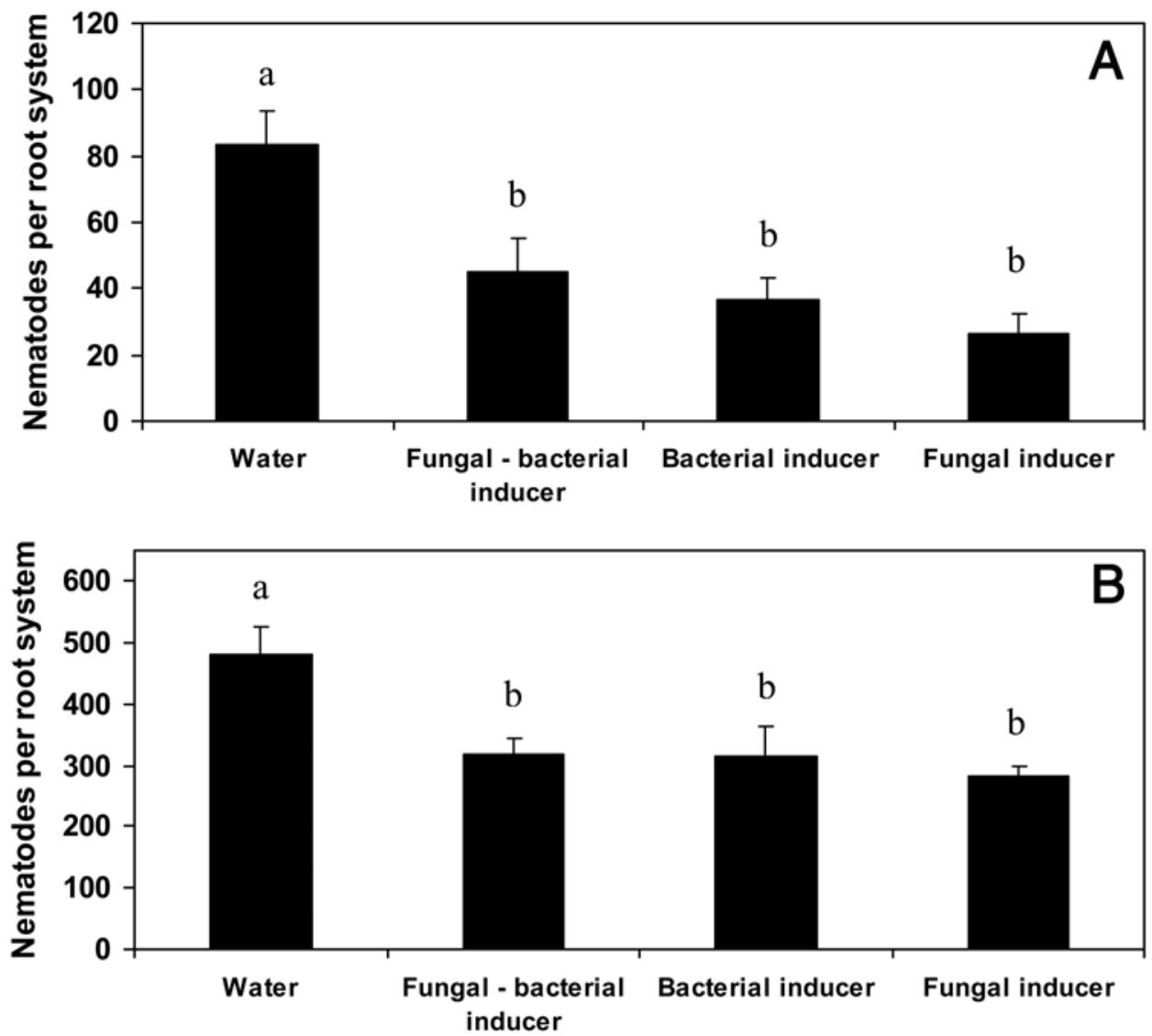

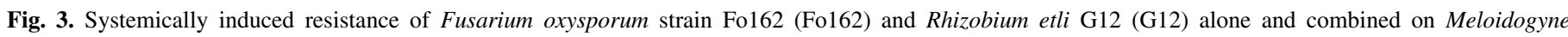

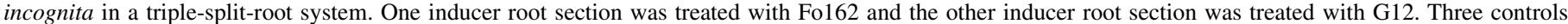

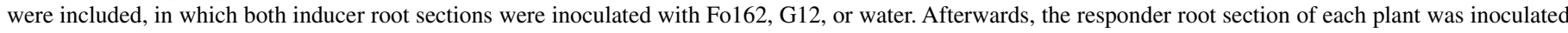

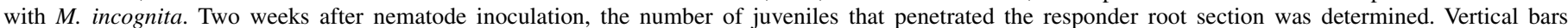

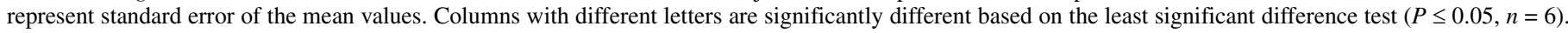
A, Experiment 1 and $\mathbf{B}$, experiment 2 .

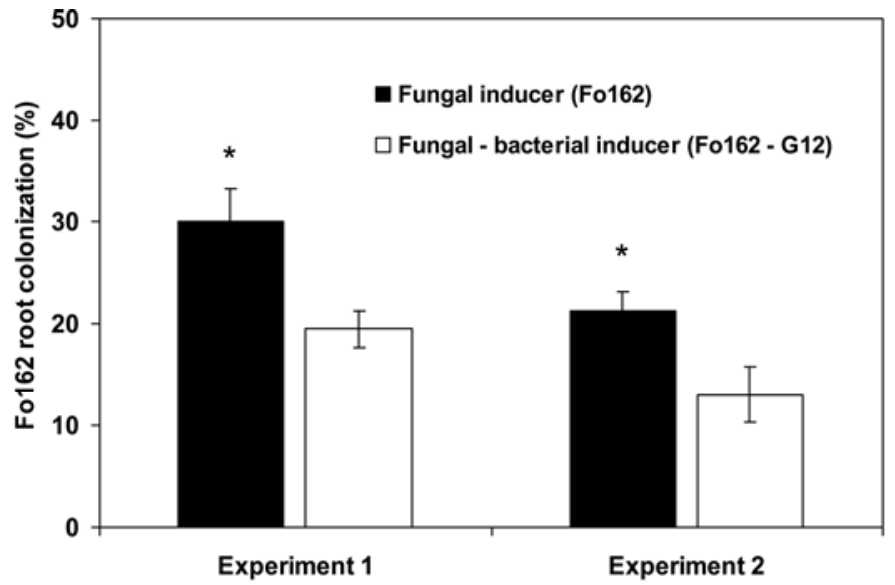

Fig. 4. Reisolation of Fusarium oxysporum strain Fo162 (Fo162) from the inducer side of a triple-split-root system. The other inducer side was either inoculated with Rhizobium etli strain G12 (G12) or Fo162 while the responder side was inoculated with Meloidogyne incognita. Six weeks after endophytes inoculation, the presence of Fo162 in the inducer section was determined. Vertical bars represent standard error of the mean values. Means with $(*)$ are significantly different for independent samples according to $t$ test $(P \leq 0.05, n=6)$.

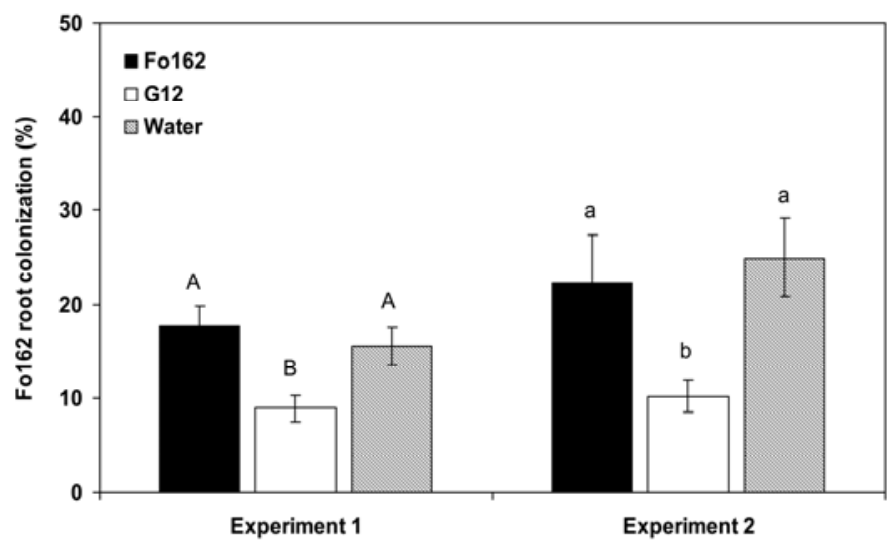

Fig. 5. Systemically induced resistance of Rhizobium etli strain G12 (G12) on Fusarium oxysporum strain Fo162 (Fo162) root colonization in a split-root system. The inducer root section of the split-root system was treated with Fo162, G12, or water. One week after, the responder half was treated with Fo162. Four weeks after inoculation of the inducer half, root colonization by Fo162 at the responder side was determined. Vertical bars represent standard error of the mean values. Columns with different letters are significantly different based on the least significant difference test $(P \leq 0.05, n=6)$. 
was effective against $M$. javanica since in $N a h G$-tomato plants, which contain the $N a h G$ gene which encodes salicylate hydroxylase that converts SA into catechol, a product that does not induce SAR, resistance was still observed.

An SA-dependent pathway has been proposed in nonpathogenic Fusarium-induced resistance toward soilborne pathogens in studies with asparagus (14); whereas a rhizobacteria-mediated induced resistance was proved to be via JA and ethylene (ET) pathways $(26,27,43)$. Several studies on the cross-talk between the JA- and SA-dependent signaling pathways have shown that negative interactions can occur, with consequences for host resistance toward pathogens $(3,11)$. The lack of additive systemic effects toward $M$. incognita observed in this study could be related to antagonism of the JA- and SA-dependent signaling pathways, but this needs to be tested. Overall, this work shows that a more detailed characterization of the defense mechanisms, triggered by the various biocontrol agents together with knowledge on the sensitivity of the individual biocontrol agents to specific defense mechanisms would help in making predictions about incompatibility and increase efficacy when microorganisms are combined to enhance biological control of pathogens and pests.

\section{ACKNOWLEDGMENTS}

We thank the German Academic Exchange Service (DAAD) for funding this research through a Ph.D. scholarship.

\section{LITERATURE CITED}

1. Backman, P. A., and Sikora, R. A. 2008. Endophytes: An emerging tool for biological control. Biol. Control 46:1-3.

2. Becker, J. O., Tavaleta-Mejia, E., Colbert, S. F., Schroth, M. N., Weinhold, A. R., Hancock, J. G., and van Gundy, S. D. 1988. Effects of rhizobacteria on root-knot nematodes and gall formation. Phytopathology 78:1466-1469.

3. Bostock, R. M., Karban, R., Thaler, J. S., Weyman, P. D., and Gilchrist, D. 2001. Signal interactions in induced resistance to pathogens and insect herbivores. Eur. J. Plant Pathol. 107:103-111.

4. Dababat, A. A., and Sikora, R. A. 2007. Induced resistance by the mutualistic endophyte, Fusarium oxysporum strain 162, towards Meloidogyne incognita on tomato. Biocontrol Sci. Technol. 17:969-975.

5. Dababat, A. A., and Sikora, R. A. 2007. Importance of application time and inoculum density of Fusarium oxysporum 162 for biological control of Meloidogyne incognita on tomato. Nematropica 37:267-275.

6. Diedhiou, P. M., Hallmann, J., Oerke, E. C., and Dehne, H. W. 2003. Effects of arbuscular mycorrhizal fungi and a non-pathogenic Fusarium oxysporum on Meloidogyne incognita infestation of tomato. Mycorrhiza 13:199-204.

7. El-Tarabily, K. A., Soliman, M. H., Nassar, A. H., Al-Hassani, H. A., Sivasithamparam, K., McKenna, F., and Hardy, G. J. 2000. Biological control of Sclerotinia minor using a chitinolytic bacterium and actinomycetes. Plant Pathol. 49:573-583.

8. Ferris, J. M. 1985. Crop loss prediction and modeling for management decisions. Pages 27-33 in: Plant Nematology-Laboratory Manual. B. M. Zuckermann, W. F. Mai, and M. B. Harrison, eds. The University of Massachusetts Agricultural Experimental Station, Amherst, MA.

9. Fuchs, J. G., Moënne-Loccoz, Y., and Défago, G. 1997. Nonpathogenic Fusarium oxysporum strain Fo47 induces resistance to Fusarium wilt in Tomato. Plant Dis. 81:492-496.

10. Hallmann, J., and Sikora, R. A. 1994. Influence of F. oxysporum, a mutualistic fungal endophyte, on $M$. incognita of tomato. J. Plant Dis. Prot. 101:475-481.

11. Hase, S., Takahashi, S., Takenaka, S., Nakaho, K., Arie, T., Seo, S., Ohashi, Y., and Takahashi, H. 2008. Involvement of jasmonic acid signaling in bacterial wilt disease resistance induced by biocontrol agent Pythium oligandrum in tomato. Plant Pathol. 57:870-876.

12. Hasky-Günther, K., Hoffmann-Hergarten, S., and Sikora, R. A. 1998. Resistance against the potato cyst nematode Globodera pallida systemically induced by the rhizobacteria Agrobacterium radiobacter (G12) and Bacillus sphaericus (B43). Fund. Appl. Nematol. 21:511-517.

13. Hasky-Günther, K., and Sikora, R. A. 1995. Induced resistance: A mechanism induced systemically throughout the root system by rhizosphere bacteria towards the potato cyst nematode Globodera pallida. Nematologica 41:306.

14. He, C. Y., and Wolyn, D. J. 2005. Potential role for salicylic acid in induced resistance of asparagus roots to Fusarium oxysporum f. sp. asparagi. Plant Pathol. 54:227-232.

15. Hooper, D. J., Llaman, J., and Subbotin, S. A. 2005. Methods for extraction, processing and detection of plant and soil nematodes. Pages 53-86 in: Plant Parasitic Nematodes in Subtropical and Tropical Agriculture, 2nd ed. M. Luc, R. A. Sikora, and J. Brige, eds. CABI Publishing, Wallingford, UK.

16. Hussey, R. A., and Barker, K. P. 1973. A comparison of methods for collecting inocula for Meloidogyne sp., including a new technique. Plant Dis. Rep. 57:1025-1028.

17. Kerry, B. R. 1990. An assessment of progress towards microbial control of plant parasitic nematodes. J. Nematol. 22:621-631.

18. Kiewnick, S., and Sikora, R. A. 2006. Biological control of the root-knot nematode Meloidogyne incognita by Paecilomyces lilacinus strain 251. Biol. Control 38:179-187.

19. King, E. O., Warth, M., and Raney, E. D. 1954. Two simple media for the demonstration of pyocyanin and fluorescin. J. Lab. Clin. Med. 44:301307.

20. Leeman, M., Pelt, J. A., van Ouden, F. M., den Heinsbroek, M., Bakker, P. A. H. M., and Schippers, B. 1995. Induction of systemic resistance by Pseudomonas fluorescens in radish cultivars differing in susceptibility to Fusarium wilt, using a novel bioassay. Eur. J. Plant Pathol. 101:655-664.

21. Liu, L., Kloepper, J., and Tuzun, S. 1995. Induction of systemic resistance in cucumber against Fusarium wilt by plant growth-promoting rhizobacteria. Phytopathology 85:695-698.

22. Martinuz, A., and Sikora, R. A. 2010. Biological control of root-knot nematodes and sucking insects by mutualistic endophytes in tomato and squash. (Abstr.) J. Plant Dis. Prot. 117:137.

23. Mendoza, A. R., and Sikora, R. A. 2009. Biological control of Radopholus similis in banana by combined application of the mutualistic endophyte Fusarium oxysporum strain 162, the egg pathogen Paecilomyces lilacinus strain 251 and the antagonistic bacteria Bacillus firmus. BioControl 54:263-272.

24. Mwangi, M., Hauschild, R., Mutitu, E. W., and Sikora, R. A. 2002. Rhizobacteria induced changes in tomato metabolism and their relationship with induced resistance against Fusarium oxysporum f. sp. lycopersici. Comm. Agric. Appl. Biol. Sci. 67:145-147.

25. Pierson, E. A., and Weller, D. M. 1994. Use of mixtures of fluorescent pseudomonads to suppress take-all and improve the growth of wheat. Phytopathology 84:940-947.

26. Pieterse, C. M. J., van Pelt, J. A., van Wees, S. C. M., Ton, J., LeonKloosterziel, K. M., Keurentjes, J. J. B., Verhagen, B. W. M., Knoester, M., van der Sluis, I., Bakker, P. A. H. M., and van Loon, L. C. 2001. Rhizobacteria-mediated induced systemic resistance: triggering, signaling and expression. Eur. J. Plant Pathol. 107:51-61.

27. Pieterse, C. M. J., van Wees, S. C. M., van Pelt, J. A., Knoester, M., Laan, R., Gerrits, H., Weisbeek, P. J., and van Loon, L. C. 1998. A novel signaling pathway controlling induced systemic resistance in Arabidopsis. Plant Cell 10:1571-1580.

28. Racke, J., and Sikora, R. A. 1992. Isolation, formulation and antagonistic activity of rhizobacteria towards the potato cyst nematode Globodera Pallida. Soil Biol. Biochem. 24:521-526.

29. Reimann, S., Hauschild, R., Hildebrandt, U., and Sikora, R. A. 2008. Interrelationship between Rhizobium etli G12 and Glomus intraradices and multitrophic effects in the biological control of the root-knot nematode Meloidogyne incognita on tomato. J. Plant Dis. Prot. 115:108-113.

30. Reitz, M., Rudolph, K., Schroeder, I., Hoffmann-Hergarten, S., Hallmann, J., and Sikora, R. A. 2000. Lipopolysaccharides of Rhizobium etli strain G12 in potato roots as an inducing agent of systemic resistance to infection by the cyst nematode Globodera pallida. Appl. Environ. Microbiol. 66:3515-3518.

31. Schäfer, K., Silva Fabry, C., Sikora, R. A., and Hauschild, R. 2006. Molecular investigations of rhizobacteria-induced systemic resistance towards the root-knot nematode Meloidogyne incognita in tomato. Multitrophic interactions in soil. IOBC/WPRS Bull. 29:135-140.

32. Selim, M. 2010. Biological, chemical and molecular studies on the systemic induced resistance in tomato against Meloidogyne incognita caused by the endophytic Fusarium oxysporum, Fo162. Ph.D. diss. University of Bonn, Bonn, Germany.

33. Siddiqui, I. A., and Shaukat, S. S. 2003. Endophytic bacteria: Prospects and opportunities for the biological control of plant-parasitic nematodes. Nematol. Mediterr. 31:111-120.

34. Siddiqui, I. A., and Shaukat, S. S. 2004. Systemic resistance in tomato induced by biocontrol bacteria against the root-knot nematode, Meloidogyne javanica is independent of salicylic acid production. J. Phytopathol. 152:48-54.

35. Sikora, R. A., Pocasangre, L., zum Felde, A., Niere, B., Vu, T. T., and Dababat, A. A. 2008. Mutualistic endophytic fungi and in planta suppressiveness to plant parasitic nematodes. Biol. Control 46:15-23.

36. Sikora, R. A., Schäfer, K., and Dababat, A. A. 2007. Modes of action 
associated with microbially induced in planta suppression of plantparasitic nematodes. Australas. Plant Pathol. 36:124-134.

37. Sikora, R. A., zum Felde, A., Mendoza, A., Menjivar, R., and Pocasangre, L. 2010. In planta suppressiveness to nematodes and long term root health stability through biological enhancement-do we need a cocktail? Acta Hort. (ISHS) 879:553-560.

38. Schulz, B., Rommert, A. K., Dammann, U., Aust, H. J., and Strack, D. 1999. The endophyte-host interaction: A balanced antagonism? Mycol. Res. 10:1275-1283.

39. Sturz, A. V., Christie, B. R., Matheson, B. G., Arsenault, W. J., and Buchanan, N. A. 1999. Endophytic bacterial communities in the periderm of potato tubers and their potential to improve resistance to soil-borne plant pathogens. Plant Pathol. 48:360-369.
40. van Loon, L. C., van Bakker, P. A. H. M., and Pieterse, C. M. J. 1998. Systemic resistance induced by rhizosphere bacteria. Annu. Rev. Phytopathol. 36:453-483.

41. van Peer, R., and Schippers, B. 1992. Lipopolysaccharides of plantgrowth promoting Pseudomonas sp. strain WCS417r induce resistance in carnation to Fusarium wilt. Neth. J. Plant Pathol. 98:129-139.

42. Vu, T. T., Hauschild, R., and Sikora, R. A. 2006. Fusarium oxysporum endophytes induced systemic resistance against Radopholus similis on banana. Nematology 8:847-852.

43. Zhang, S., Moyne, A. L., Reddy, M. S., and Kloepper, J. W. 2002. The role of salicylic acid in induced systemic resistance elicited by plant growth-promoting rhizobacteria against blue mold of tobacco. Biol. Control 25:288-296. 